\title{
PHYSIOLOGICAL AND PROTEOMIC RESPONSES OF DENDROCALAMUS MINOR VAR. AMOENUS (GHOST BAMBOO) UNDER DROUGHT STRESS
}

\author{
HE, T. Y. ${ }^{1}-$ FAN, L. L. ${ }^{2}-$ TARIN, M. W. K. ${ }^{1}-$ SHEN, S. Y. ${ }^{1}-$ XIE, D. J. ${ }^{2}-$ CHEN, L. Y. ${ }^{1}-$ RoNG, \\ J. D. ${ }^{2}-$ CHEN, L. G. ${ }^{2}-$ ZHENG, Y. S. ${ }^{1,2^{*}}$ \\ ${ }^{I}$ College of Arts \& College of Landscape Architecture, Fujian Agriculture and Forestry \\ University, Fuzhou 350002, Fujian Province, PR China \\ ${ }^{2}$ College of Forestry, Fujian Agriculture and Forestry University, Fuzhou 350002, Fujian \\ Province, PR China \\ *Corresponding author \\ e-mail: zys1960@163.com; phone: +86-0591-8375-8750
}

(Received $9^{\text {th }}$ Dec 2019; accepted $6^{\text {th }}$ May 2020)

\begin{abstract}
Dendrocalamus minor var. amoenus was analyzed for physiological and proteomic responses under drought stress. The adverse effects of drought on $D$. minor var. amoenus were primarily affected by gas exchange attributes such as photosynthesis (Pn), stomatal conductance (Gs), and transpiration rate (Tr) decreased as drought intensity increased. Among chlorophyll fluorescence parameters, actual photochemical efficiency of PSII (ФPSII), electron transport rate (ETR), and non-photochemical quenching $(\mathrm{qN})$ also decreased under increasing drought stress throughout the natural dehydration process (15-30 days). Moreover, superoxide dismutase (SOD) and catalase (CAT) levels increased significantly when subjected to short drought event and then decreased rapidly under severe drought stress. Using twodimensional gel electrophoresis (2-DE), we detected more than 500 protein spots; 41 significant differentially expressed protein spots were uncovered under drought stress. Following matrix-assisted laser desorption/ionization time-of-flight mass spectrometry (MALDI-TOF-MS) identification and BLAST of these 41 proteins spots to an NCBI or Uniprot database, 33 differential protein spots were identified. In addition to determining a suitable protocol for protein extraction from $D$. minor var. amoenus (or other bamboo species), this study provides important information on signal transduction pathway changes under drought stress for exploring drought resistance candidate genes in bamboo species.
\end{abstract}

Keywords: gas exchange, chlorophyll fluorescence, gel electrophoresis, proteins spots

\section{Introduction}

In recent years, the greenhouse effect has led to increasingly more severe environmental conditions related to global warming (Khaliq et al., 2019). In many locations, extreme drought disasters have occurred, seriously threatening the agricultural and silvicultural production as well as ecological and environmental protection efforts (Thalmann and Santelia, 2017). Drought is a significant abiotic stress factor that affects the growth and development of plants (Tayyab et al., 2018). Plant growth changes and response mechanisms under water deficit conditions have always been important scientific research subjects. Plants reduce damage caused by drought stress through changes in morphological structure, physiological responses, and biochemical processes, such as growth rate, stomatal conductance, tissue permeability, and antioxidant defense (Caruso et al., 2008; Tarin et al., 2020). When subjected to drought deficit conditions, plant responses vary greatly at three different levels; wholeplant, cellular, and molecular (Chalker-Scott, 1999). 
At the whole-plant level, drought deficit condition often leads to internal water imbalances, decreases cell water potential, and turgor pressure, resulting in shoot and leaf wilting and drooping. If such conditions persist, plants often lead to serious water loss from cell protoplasts and eventually plant death (Tarin et al., 2018). The adverse effects of drought stress have frequently manifested a decrease in phenotypic growth and photosynthesis, which are factors associated with changes in substance metabolism (Lawlor and Cornic, 2002; Rouhi et al., 2007; Koh et al., 2015). Photosynthetic activity and plant leaf structure are significantly impaired due to declines in stomatal closure and photosynthesis-related enzymes under drought stress (Chaves et al., 2009; Aranjuelo et al., 2010). The decrease in photosynthetic activity is caused by both stomatal and non-stomatal limitations. Under mild stress conditions, a stomatal limitation is a primary factor affecting photosynthesis; however, when severe stress damages photosynthetic organs and their structure, photosynthesis becomes increasingly influenced by non-stomatal limitation in chloroplast $\mathrm{CO}_{2}$ fixation ability, rather than $\mathrm{CO}_{2}$ diffusion resistance (Bota et al., 2004; Grassi and Magnani, 2005; Lawlor and Tezara, 2009).

At the cellular level, drought deficit conditions often lead to the accumulation of numerous substances that regulate osmotic pressure, including proline (PRO), soluble sugar, betaine, etc. (Kaushal and Wani, 2016). These substances increase cytoplasmic concentration levels, lower osmotic potential, and help maintain cell turgor pressure, allowing cells to continue to absorb water from the environment, sustaining plant morphological and physiological characteristics (Costa et al., 1998). Additionally, drought deficit conditions often lead to the accumulation of antioxidant enzymes (e.g., SOD and CAT), which enhance the capabilities of scavenging reactive oxygen species (ROS) such as $\mathrm{H}_{2} \mathrm{O}_{2}$ and $\mathrm{O}^{2-}$, reducing their adverse effect on normal photosynthetic functions (Luna et al., 2004; Wang et al., 2009; Caverzan et al., 2016).

At the molecular level, drought deficit conditions often alter gene expression and protein synthesis (upregulation and downregulation), leading to changes in biological functions. Several molecular mechanisms of drought stress in many plants, including Arabidopsis (Zou et al., 2010), rice (Yang et al., 2012) and maize (Liu et al., 2013), were studied and elucidated by describing the quantitative trait locus (QTL), gene cloning, mutant screening, expression profiling, and functional verification of candidate genes. Specifically, the Arabidopsis thaliana glutathione peroxidase 3 (ATGPX3) enzyme can regulate abscisic acid (ABA) and initiate oxidative signal transduction in response to drought, leading to dynamic $\mathrm{H}_{2} \mathrm{O}_{2}$ balance in the cell (Miao et al., 2006). Unlike DNA or RNA, proteins can be directly involved in plant stress responses, and proteomics research can more intuitively reveal relationships between protein abundance and plant stress responses (Kosová et al., 2011).

Expression changes in plant proteins under drought stress can be divided into three categories: (1) signaling cascades and transcription-related proteins (e.g., protein kinase, protein phosphatase, and transcription factors); (2) functional proteins that protect the cell membrane and related proteins (e.g., embryonic period proteins, antioxidants, and osmotic-adjustment proteins); and (3) proteins associated with water and ion absorption (e.g., aquaporin and sugar transporters) (Fang and Xiong, 2015). Previous research using isobaric tags for relative and absolute quantitation (iTRAQ) and two-dimensional difference in gel electrophoresis (2D-DIGE) technology in desert poplar (Populus euphratica) (Bogeat-Triboulot et al., 2007), soybean (Glycine max) (Alam et al., 2010) and rapeseed (Brassica napus) (Koh et al., 2015) used proteomic analysis to reveal the 
effects of drought stress and related response mechanisms. Consequently, proteomic analysis can be used to identify several proteins involved in oxidative stress detoxification, signaling pathways, and protein folding.

D. minor var. amoenus is an important ornamental bamboo species of economic importance. Known for its exotic coloration, this plant exhibits several dark green vertical stripes interspersed with light yellow at the internodes. This bamboo species was introduced in coastal sandy areas in Fujian province as a novel windbreak and dune-fixing plant species for use in a mixed planting with wetland pine. In recent years, D. minor var. amoenus has been widely used in landscape and forest protection efforts. However, bamboo introduction to coastal sandy shelterbelt areas and its use in forest protection programs have been adversely affected because soil moisture and nutrient content are relatively low in coastal sandy soils, and environmental conditions for planting in these locations are poor. Continuous drought has also seriously affected both the ornamental characteristics of the bamboo and the survival rate of new bamboo shoots, especially during out-shoot periods. Recently, there are few studies on the drought-resistance mechanism of bamboo species with a focus on the physiology, biochemical attributes, photosynthetic pigments, water potential, photosynthetic activity (Wu et al., 2019; Tong et al., 2020). However, studies on the physiological and proteomic responses of $D$. minor var. amoenus under drought stress have received nearly no prior research. Therefore, efforts to investigate drought response mechanisms and enhance stress tolerance in D. minor var. amoenus will be vital to enhance landscape benefits and bamboo shoot production.

In this study, we conducted an integrated physiological and proteomic analysis of $D$. minor var. amoenus under drought stress. First, we optimized the protocol for protein extraction in bamboo species D. minor var. amoenus. We then assessed several physiological responses, biochemical processes, and different proteome expressions of the plant under drought stress. These results will contribute to the knowledge and understanding of the response mechanisms of bamboo species under drought stress. Additionally, they provide important information on changes in the signal transduction pathway in bamboo species under drought stress and provide an experimental basis for exploring drought resistance candidate genes of bamboo species through proteomic methods. This study is also of significant importance for future exploration of molecular genetics and transgenic breeding of bamboo species.

\section{Materials and methods}

\section{Plant materials}

Two-year-old D. minor var. amoenus plants were obtained from bamboo coastal sandy protection areas (Dongshan Island, Fujian, China) with similar growth conditions and directly transplanted to the Bamboo Research Institute of the Fujian Agriculture and Forestry University (Fig. Al in the Appendix). Seedlings were cultivated in plastic basins (height $=180 \mathrm{~mm}$ and diameter $=240 \mathrm{~mm}$ ), containing a mixed nutrient medium of peat and matrix (1:2) in a greenhouse. The environmental conditions were $32 / 20{ }^{\circ} \mathrm{C}$ (day/night) with a photoperiod of $14 \mathrm{~h}$ under natural daylight, the relative humidity of $75-85 \%$, and photosynthetically active radiation of $900 \mu \mathrm{mol} \mathrm{m} \mathrm{m}^{-2} \cdot \mathrm{s}^{-1}$. Plants were irrigated with tap water every day to reach maximum water holding capacity. Drought stress was initiated after 6 months of normal growth. Half the bamboo plants continued to be irrigated regularly maintained in optimal water availability conditions, whereas the 
other half (randomly selected) was not irrigated to exposed to natural drought conditions (with water withholding). Over a month, drought plants were grown without any watering, whereas control plants were watered until basins capacity. Plant leaves used for physiological analysis were harvested at days $0,5,10,15,20,23,26$, and 30, whereas leaves used for proteome analysis were harvested at days 0 and 26. In total 20 pots were handled (10 for drought conditions and 10 for control). At each sampling time, three biological replicates (3 or more than 3 independent pots, randomly selected with leaves at the same internode position) for each exploration were examined. Leaf samples were selected and kept on ice. Residual dirt was removed from the leaves with double-distilled water. Materials were immediately frozen in liquid nitrogen and stored at $-80{ }^{\circ} \mathrm{C}$ before protein extraction and enzyme measurement.

\section{Determination of soil water content and leaf water potential}

Soil water content (SWC) and leaf water potential (LWP) of the bamboo plants were measured at days $0,5,10,15,20,23,26$, and 30, after cessation of irrigation. LWP of the bamboo leaves was measured at different time intervals using a WP4-T potential meter (Decagon, USA) as described in a previous study (Ebrahimi-Birang and Fredlund, 2016). SWC was measured at the same time intervals as LWP, using a TZS soil moisture meter (TUOPU, China). At each sampling time, three replicates were measured for SWC and LWP.

\section{Determination of photosynthetic and chlorophyll fluorescence parameters}

Bamboo leaves were enclosed in an LI-6400XT portable photosynthesis system (LICOR, USA) for 2.5 h from 9:00 to 11:30 am during each time node for measurement of photosynthetic parameters, including net photosynthetic rate $(\mathrm{Pn})$, intercellular $\mathrm{CO}_{2}$ concentration $(\mathrm{Ci})$, stomatal conductance $(\mathrm{Gs})$, and transpiration rate $(\mathrm{Tr})$. Photosynthetic photon intensity and $\mathrm{CO}_{2}$ levels inside the leaf chamber were maintained at 1000 $\mu \mathrm{mol} \mathrm{m}{ }^{-2} \cdot \mathrm{s}^{-1}$ and $400 \mathrm{mmol}^{-1} \cdot \mathrm{s}^{-1}$, respectively. Water use efficiency (PWUE) and stomatal limitation values (Ls) were calculated by the following equations (Deeba et al., 2012):

$$
\begin{aligned}
& \text { Water use efficiency }=\mathrm{Pn} / \mathrm{Tr} \\
& \text { Stomatal limitation }=\mathrm{Ci} / \mathrm{Co}
\end{aligned}
$$

where $\mathrm{Pn}$ is the net photosynthetic rate, $\mathrm{Tr}$ is transpiration rate, $\mathrm{Ci}$ is intercellular $\mathrm{CO}_{2}$ concentration, and $\mathrm{Co}$ is the concentration of $\mathrm{CO}_{2}$ outside the leaf, respectively.

The maximum photochemical efficiency of PSII (Fv/Fm) was measured after plant leaves had been pre-dark-adapted for 20 min within an OS5P fluorescence chamber (Opti-Sciences, USA). The actual photochemical efficiency of PSII (ФPSII), the relative rate of photosynthetic electron transport (ETR), and non-photochemical quenching coefficient $(\mathrm{qN})$ were determined simultaneously using the same device. Calculations for these parameters were done according to the instrument manufacturer's instructions (Sobrado, 2011).

\section{Content or activity of antioxidant enzyme and osmosis substance}

To determine the content or activity of physiological enzymes precisely weighed leaves were mechanically ground to powder in liquid $\mathrm{N}_{2}$ and then homogenized in 4- 
fold $0.9 \%$ saline solution (V/W) to generate a $20 \%$ tissue homogenate. Homogenates were centrifuged at $4500 \times g$ for $10 \mathrm{~min}$ and the supernatants were used for enzyme analysis. Superoxide dismutase (SOD), catalase (CAT), malondialdehyde (MDA), and proline (PRO) levels were examined using the corresponding assay kits according to the manufacturer's instructions (Nanjing Jiancheng Bioengineering Institute, Nanjing, China). Values were normalized following protein concentration determination via Coomassie Brilliant Blue method (Bradford, 1976).

\section{Total proteins sample extraction}

A process workflow for total protein extraction of $D$. minor var. amoenus leaves is shown in Figure 1. Detailed experimental methods follow: frozen leaves with midribs removed $(0.2 \mathrm{~g})$ were ground into powder in liquid $\mathrm{N}_{2}$ in a pre-cooled mortar. The powder was incubated in $1 \mathrm{~mL}$ pre-chilled NP-40 protein extract buffer $(0.5 \mathrm{M}$ Tris$\mathrm{HCl}, \mathrm{pH} 82 \%$ [v/v]; $\beta$-mercaptoethanol, $2 \%$ [v/v] NP-40; $20 \mathrm{mM} \mathrm{MgCl} 2 ; 1 \mathrm{mM}$ EDTA; $1 \mathrm{mM}$ PMSF; and 1\% PVPP). Following ultrasonication, five volumes TCA/acetone extract solution $(10 \%[\mathrm{w} / \mathrm{v}] \mathrm{TCA}$ and $0.07 \%[\mathrm{v} / \mathrm{v}] \beta$-mercaptoethanol) were added and the sample was kept at $-20{ }^{\circ} \mathrm{C}$ overnight to ensure complete protein precipitation. Sedimentation was centrifuged at $4{ }^{\circ} \mathrm{C}$, at $16000 \times g$ for $15 \mathrm{~min}$, and the supernatant was discarded and the pellets were rinsed four times with five volumes pre-chilled TCA/acetone extract solution. The solution was left standing at $-20{ }^{\circ} \mathrm{C}$ for $30 \mathrm{~min}$ after the addition of the extract solution for each rinse. The resultant precipitate comprised the total proteins in the leaves of D. minor var. amoenus. After vacuum drying, pellets were lysed with rehydration solution (4\% CHAPS, $40 \mathrm{mM}$ DTT, $7 \mathrm{M}$ urea, $2 \mathrm{M}$ thiourea, and small amounts of protease inhibitors), considered the total protein sample in this work, and stored at $-80{ }^{\circ} \mathrm{C}$ (Wang et al., 2006).



Figure 1. Schematic workflow of total protein precipitation for D. minor var. amoenus proteome 


\section{Two-dimensional gel electrophoresis (2-DE)}

Two-dimensional gel electrophoresis (2-DE) experiment was conducted following the BIO-RAD 2-DE Instruction Manual. Samples were loaded on $17 \mathrm{~cm} \mathrm{pH} \mathrm{5-8}$ immobilized $\mathrm{pH}$ gradient (IPG) strips (BIO-RAD, USA) by passive rehydration via absorption for $24 \mathrm{~h}$ with a loading weight and loading volume of $20 \mu \mathrm{g}$ and $125 \mu \mathrm{L}$, respectively. A PROTEAN ${ }^{\circledR} \mathrm{i} 12^{\mathrm{TM}}$ IEF system was used to perform isoelectric focusing (IEF) at $20^{\circ} \mathrm{C}$ and the current was limited to $50 \mu \mathrm{A}$ per strip. IEF parameters were set as follows: $250 \mathrm{~V}(30 \mathrm{~min}), 500 \mathrm{~V}(30 \mathrm{~min}), 4000 \mathrm{~V}$ (boost for $3 \mathrm{~h}$ ), $4000 \mathrm{~V}$ (focusing with $20000 \mathrm{~V}-\mathrm{h}$ ), and $500 \mathrm{~V}$ (hold).

Two experimental groups were frozen at $-20{ }^{\circ} \mathrm{C}$ immediately, whereas a two-step balancing process was performed on another repeating group following first dimension electrophoresis. Equilibrate buffer $(2 \%$ [w/v] SDS, $6 \mathrm{M}$ urea, 20\% [v/v] glycerol, $0.05 \mathrm{M}$ Tris- $\mathrm{HCl}, \mathrm{pH} 8.8$, and 2\% DTT) was used in the first balancing process for $15 \mathrm{~min}$. In the second balancing process, equilibrate buffer (same as the first process, except that IAA was substituted for DTT) was also used for $15 \mathrm{~min}$. SDS-PAGE was performed immediately after all equilibration steps were completed, using $12 \%$ separation gel and $120 \mathrm{~V}$ gel electrophoresis parameters, until the bromophenol blue indicator reached the gel base. After the second dimension electrophoresis, the gels were stained using a modified silver-staining method (Yan et al., 2000).

Gel with protein spots was visualized after silver staining. The spots were scanned using a UMAX Power Look 2100XL scanner (UMAX Systems, Willich, Germany) at 1000 dpi resolution in TIF format. PDQuest version 8.0.1 software (BIO-RAD, USA) was used to calculate and analyze protein spot images according to the manufacturer's instructions. Additional modifications were performed manually, after automated software detection, matching, and normalization, to reduce the potential for discrepancies during spot selection (Liu et al., 2015).

\section{In-gel digestion and MALDI-TOF-MS identification}

Differentially expressed protein spots were manually cut from the gels and were subjected to decolorization, in-gel trypsin digestion, and peptide extraction. Peptide mass fingerprint (PMF) spectrum analysis was then conducted using a 5800 MALDITOF-MS analyzer (Applied Biosystems, USA). Retrieval result reliability was evaluated using a ratio of peptide segment matching rate, protein score, and a sequence coverage of matched peptides in the corresponding protein, and then analyzed using biological mass spectrometry methods. A BLAST of MS spectra against the Uniprot and NCBI databases, using MASCOT2.2 software (Matrix Science, UK), was performed to search for PMF. Minimum ion scores for each identified MS data point were capped at or above 95\% C. I. (Alam et al., 2010; Liu et al., 2015) to ensure result credibility.

\section{Statistical and bioinformatics analysis}

All parameters at different stress periods were statistically analyzed using SPSS 19.0 software (SPSS Science, USA). Data are reported as means with $( \pm$ ) standard deviation (SD). Multiple ANOVA comparisons were made using three replications; significance level was set at $P<0.05$. Specifically, we calculated Pearson's correlation coefficient between photosynthetic parameters, SWC, and LWP. 
Bioinformatics analysis of the biological functions of differential proteins was performed using the Kyoto Encyclopedia of Genes and Genomes (KEGG) and Gene Ontology (GO) online analysis software. KEGG is a collection of pathway maps representing molecular interaction network information (Li et al., 2016), whereas GO is a classification system for gene function clusters that provide descriptions for genes and gene product attributes in organisms. GO uses three ontologies that describe the molecular function, cellular components, and biological processes (Li et al., 2016).

\section{Results}

\section{Soil water content and leaf water potential}

Soil water content (SWC) and leaf water potential (LWP) showed steadily decreasing trends throughout the treatment period, although no significant SWC trend differences were observed on days 15 and 20 (Table Al in the Appendix). SWC and LWP levels in the control group were maintained at $30-40 \%$ and $-1.0--1.3 \mathrm{MPa}$, respectively, throughout the treatment period. SWC and LWP levels in the treatment group were lowered dramatically by $98 \%$ and $79 \%$ to $0.43 \%$ and $-5.65 \mathrm{MPa}$, respectively. LWP decreased sharply when the treatment period was extended, whereas SWC declined slowly during days 20-30; however, this decrease was lower than that of LWP during the same timeframe.

\section{Photosynthetic parameters}

Photosynthetic parameters, including net photosynthesis (Pn), stomatal conductance (Gs), and transpiration rate ( $\mathrm{Tr}$ ), decreased significantly as the drought period was prolonged, although fluctuations in this trend were observed on days 10 and 23 (Fig. 2). However, declines in Pn, Gs, and Tr were slower than those in SWC. Pn, Gs, and Tr decreased by $4.38 \mu \mathrm{mol} \mathrm{CO} \mathrm{Cm}^{-2} \cdot \mathrm{s}^{-1}, 0.11 \mathrm{~mol} \mathrm{H}_{2} \mathrm{O} \mathrm{m}^{-2} \cdot \mathrm{s}^{-1}$, and $2.59 \mathrm{mmol} \mathrm{H} \mathrm{O} \mathrm{m}^{-2} \cdot \mathrm{s}^{-1}$, respectively during drought period days 0-23. Similar decreases in $\mathrm{Pn}, \mathrm{Gs}$, and $\mathrm{Tr}$ were noted $\left(3.12 \mu \mathrm{mol} \mathrm{CO} \mathrm{m}^{-2} \cdot \mathrm{s}^{-1}, 0.03 \mathrm{~mol} \mathrm{H}_{2} \mathrm{O} \mathrm{m}^{-2} \cdot \mathrm{s}^{-1}\right.$, and $1.32 \mathrm{H}_{2} \mathrm{O} \mathrm{m}^{-2} \cdot \mathrm{s}^{-1}$, respectively) during days 23-30. Figure 2 illustrates that $\mathrm{Pn}$ is more sensitive in terms of drought response than either $\mathrm{Gs}$ or $\mathrm{Tr}$, decreasing by $7.50 \mu \mathrm{mol} \mathrm{CO}_{2} \mathrm{~m}^{-2} \cdot \mathrm{s}^{-1}$ overall. No significant changes were observed in $\mathrm{Ci}$ during drought period days $0-15$ compared to the control group; however, $\mathrm{Ci}$ also showed a downward trend during days 15-26, reaching a minimum of $395.68 \mu \mathrm{mol} \mathrm{CO} \mathrm{Col}^{-1}$ on day 26. PWUE increased initially, and then decreased slowly during days 5-20, before sharply decreasing after day 26. Similarly, Ls showed an upward trend during days 10-26, and then sharply decreased after days 26.

Besides, Pn, Gs, and Tr were significantly correlated with LWP $(P<0.01)$, and Pn was significantly correlated with both Gs and $\operatorname{Tr}(P<0.01)$. Pn, Gs, and $\operatorname{Tr}$ were also found to be significantly correlated with SWC $(P<0.01)$ after correlation analysis was conducted between photosynthetic parameters, SWC, and LWP (Table A2).

\section{Chlorophyll fluorescence parameters}

Intrinsic photosynthetic efficiency of PSII ( Fv/Fm) showed a decreasing trend throughout the drought stress period, and actual photochemical efficiency ( $\phi$ PSII) underwent a similar trend, both declining to minimum levels at day 30 by $28 \%$ and $82 \%$, respectively (Fig. 3). Additionally, slight increases in the non-photochemical 
quenching coefficient (qN) were observed during days 5-15, but this parameter subsequently declined after day 15. Similarly, the apparent electron transfer rate (ETR) in the drought stress group increased slowly during days 0-10 but gradually decreased after day 10 (Fig. 3).



Stress days

Figure 2. Changes in photosynthetic parameters in leaves of D. minor var. amoenus under drought stress. Parameters include net photosynthetic rate (Pn), stomatal conductance (Gs), transpiration rate (Tr), intercellular $\mathrm{CO}_{2}$ concentration (Ci), water use efficiency (PWUE), and stomatal limitation value $(L s)$. Vertical bars represent the standard deviations

\section{Antioxidant enzymes and osmotic substances}

As drought conditions persisted, both PRO and MDA levels increased over time. Compared to the control group, during days 10-30, PRO levels increased 15-fold to $365 \mu \mathrm{g} . \mathrm{g}^{-1}$, whereas MDA levels increased 3-fold to $14.6 \mathrm{nmol} \mathrm{mg}^{-1}$ prot. In response to drought stress, many plants increase antioxidant enzyme levels to remove ROS. Levels of two antioxidant enzymes, CAT and SOD, were measured to gauge damage response. Similar outcomes were produced in these two enzymes by drought stress, and a significant increase in SOD and CAT levels on day 10 was observed. However, a significant decrease in these two enzymes was also observed after day 10 (Fig. 4). 


\section{Two-dimensional gel electrophoresis (2-DE) analysis}

The 2-DE process was repeated thrice for each treatment group; representative gels are shown in Figure 5. More than 500 total protein spots were detected in silver-stained gels in each treatment. Several protein spots observed to have significant changes in abundance were also identified. These spots were identified using MALDI-TOF-MS for PMF identification. Among these, 41 protein spots were common to all gels and these were subjected to MS identification. Following MS identification, 33 protein spots were successfully identified (Table A3). Additionally, 23 protein spots were upregulated, 13 spots were downregulated, and 5 newly expressed spots were identified. Enlarged profiles of the 41 differentially expressed protein spots under drought stress are shown in Figure 6.

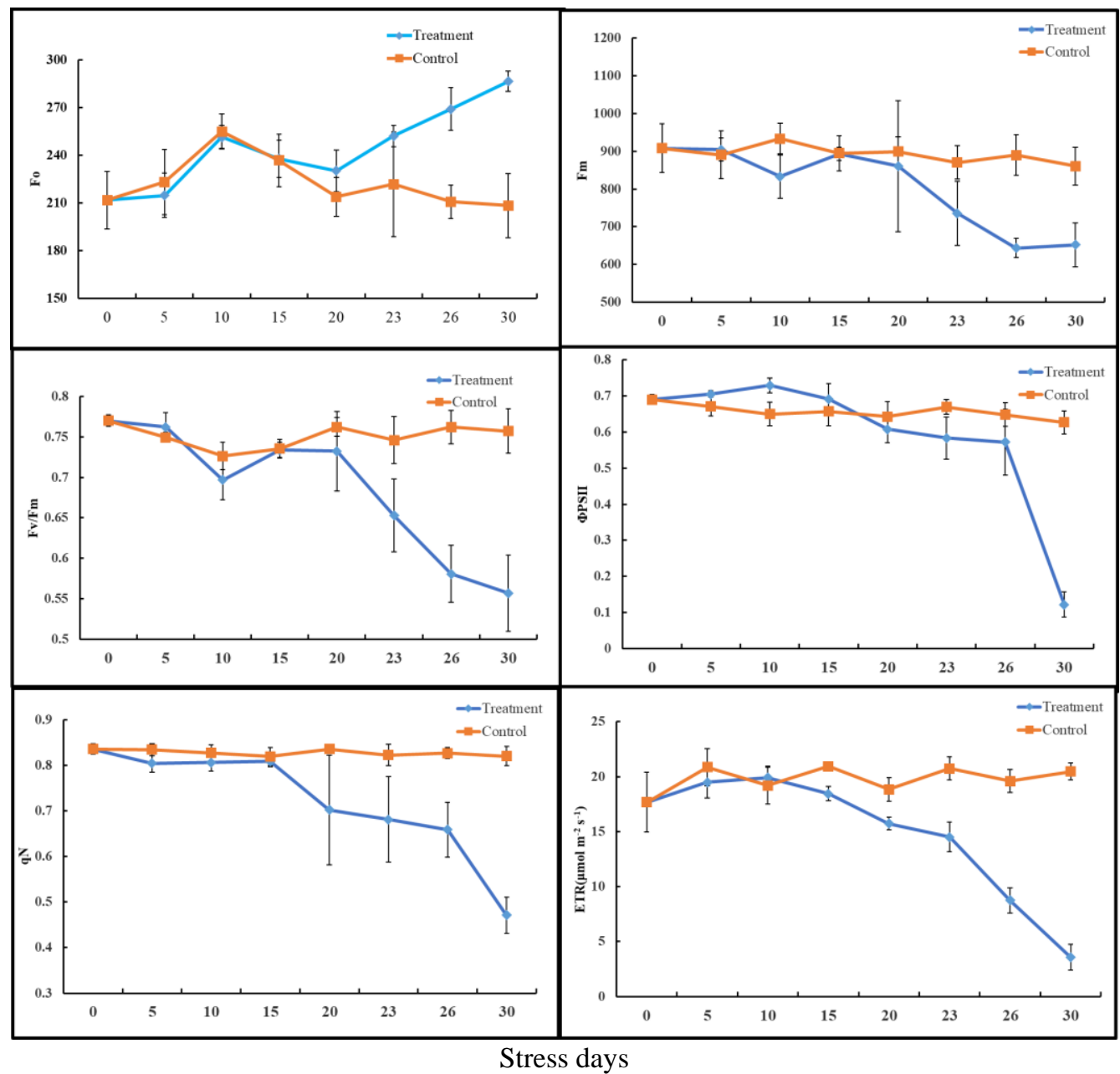

Figure 3. Changes in chlorophyll fluorescence parameters in leaves of D. minor var. amoenus under drought stress. Parameters include initial minimum fluorescence (Fo), maximum fluorescence $(\mathrm{Fm})$, quenching parameter $(q N)$, maximum quantum yield of PSII $(\mathrm{Fv} / \mathrm{Fm})$, effective quantum yield ( $(P S I I)$, electron transport rates (ETR). Vertical bars represent the standard deviations of the mean

\section{Upregulated protein spots}

Upregulated protein spots were identified as oxygen-evolving enhancer protein 1 (spot 4), extra-large guanine nucleotide-binding protein 3-like isoform X2 (spot 21), 2Cys peroxiredoxin BAS1 (spot 22), oxygen-evolving enhancer protein 2 (spot 23), 
calcium-dependent protein kinase (spot 29), PsbP chain A (spot 30), malate dehydrogenase (spot 31), flavin-containing monooxygenase (spot 35), glutathione Stransferase DHAR3 (spot 38), cytochrome b6-f complex iron-sulfur subunit (spot 39), and germin-like protein 8-14 (spot 40). Many upregulated proteins were associated with signaling transduction (e.g., spots 29 and 39), whereas some proteins (e.g., spots 4 and 23) were associated with photosynthesis.
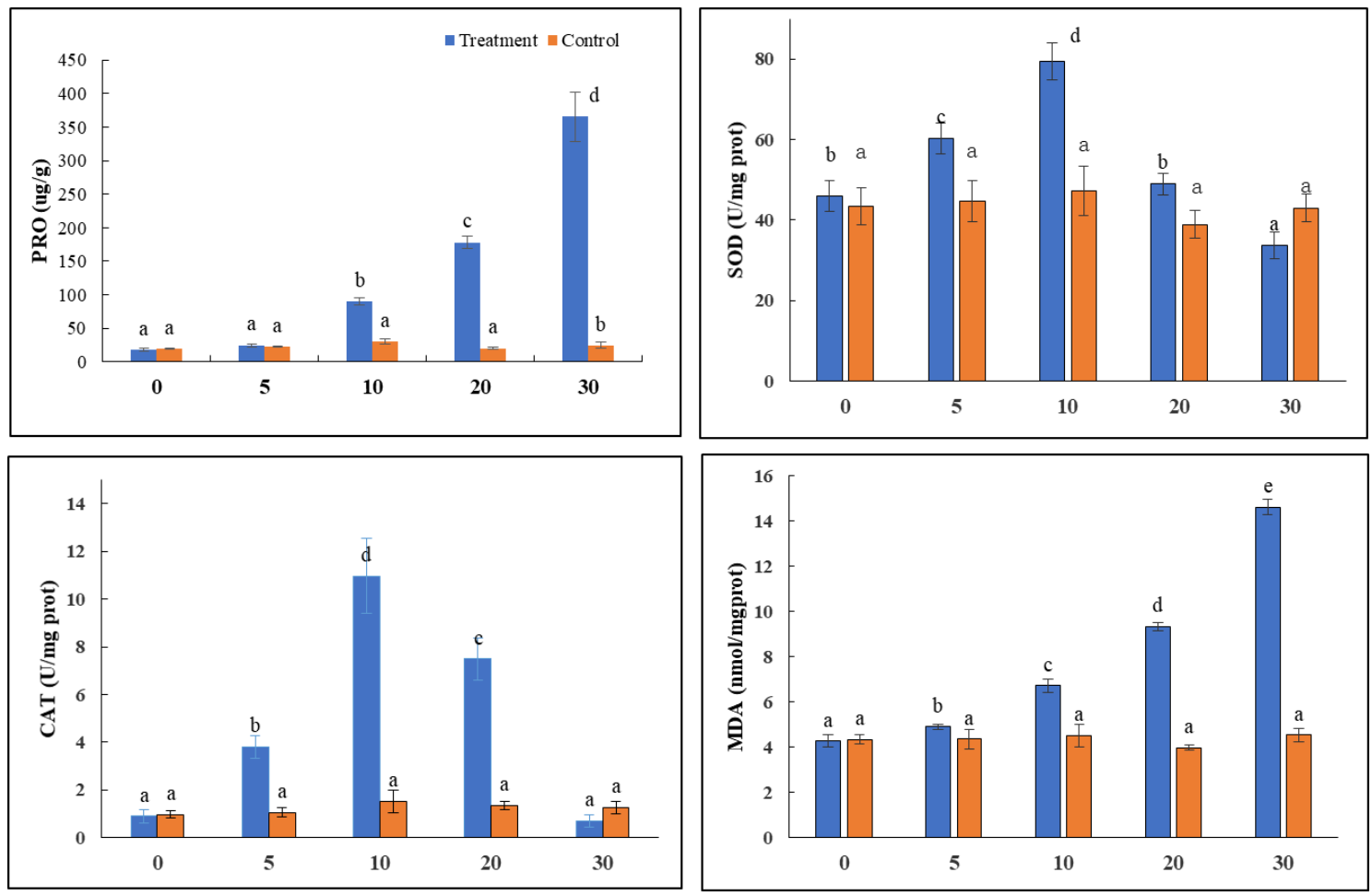

Stress days

Figure 4. Changes in proline (PRO), superoxide dismutase (SOD), catalase (CAT), and malondialdehyde (MDA) in leaves of D. minor var. amoenus under drought stress. Different letters indicate significant differences $(P<0.05)$ among various treatments with vertical bars as standard deviations

\section{Downregulated protein spots}

Downregulated protein spots were identified as ribulose-1,5-bisphosphate carboxylase/oxygenase large subunit (spot 1), ribulose bisphosphate carboxylase small chain (spot 4), RuBisCO small subunit C (spot 5), ribosome-recycling factor (spot 16), ribulose bisphosphate carboxylase/oxygenase activase (spot 18), eukaryotic translation initiation factor 3 subunit A (spot 26), fructose-bisphosphate aldolase (spot 33), and ATP synthase CF1 beta subunit (spot 41). Many downregulated proteins were associated with photosynthesis (e.g., spots 1, 4, and 5), energy metabolism (e.g., spot 41), and translation (e.g., spot 26).

\section{Newly expressed protein spots}

Newly expressed protein spots included ferritin-1 (spot 10), transcription factorrelated family protein (spot 14$)$, and rca1 (spot 34$)$. 

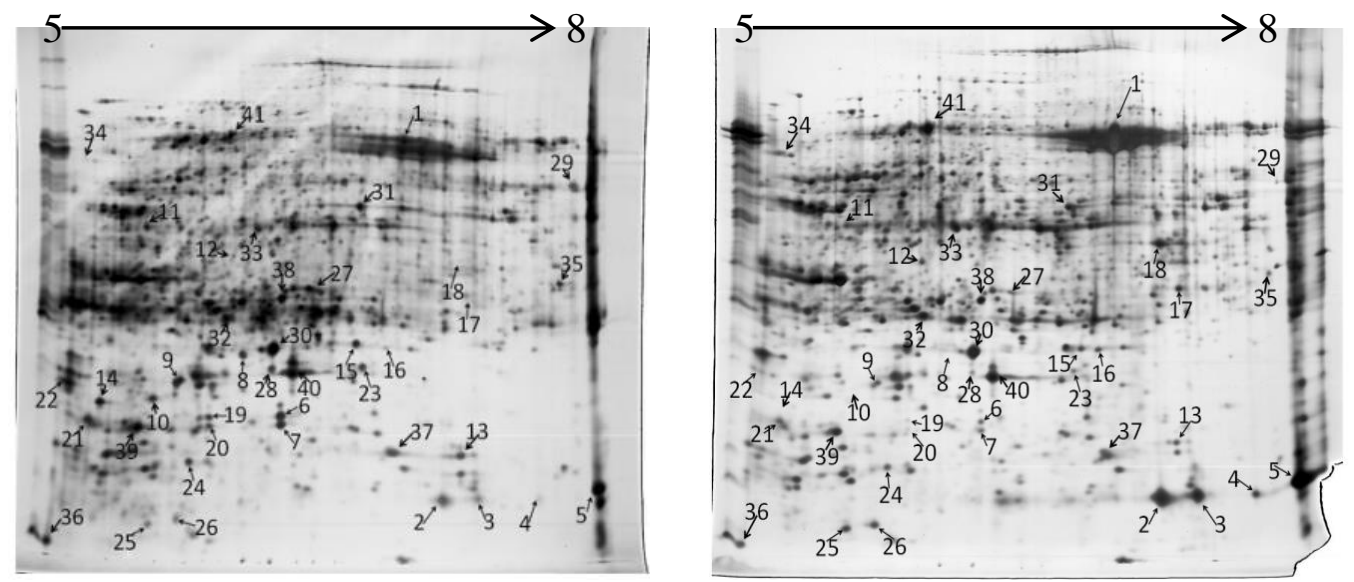

Figure 5. Silver-stained two-dimensional proteome profiles gel of proteins extracted from leaves of D. minor var. amoenus grown under drought (left, day 0) and drought (right, day 26) conditions. In the first dimension, total protein was loaded on a $17 \mathrm{~cm}$ IEF strip with a linear gradient of $\mathrm{pH} 5-8$. The second dimension was conducted in $12 \%$ polyacrylamide $(w / v)$ gels $(20 \mathrm{~cm})$ (for details, see Materials and methods). The gel image analyses conducted with PDQuest software. The subsequent mass spectrometry analyses identified up to 41 proteins (marked by arrows) that were involved in the plant response to drought
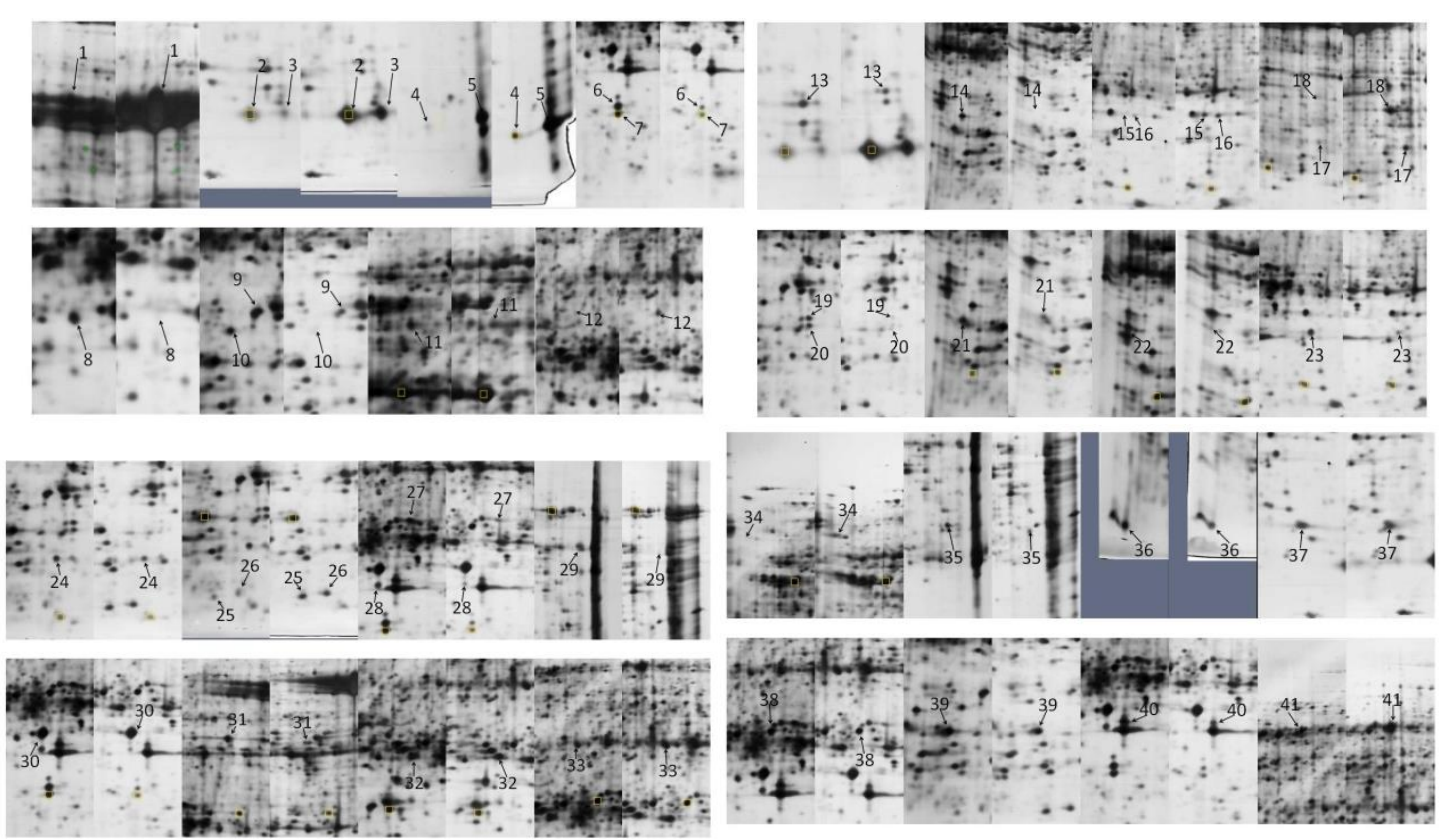

Figure 6. Enlarged profiles of silver-stained gel of 41 differentially expressed protein spots in Figure 5 that under drought (left, day 26) and control (right, day 0) conditions. Among the same letter, left for the control group and right for the drought experimental group. The subsequent mass spectrometry analyses identified up to 41 proteins (marked by arrows) that were involved in the plant response to drought

\section{Bioinformatics analysis}

Thirty-three differential abundance proteins were examined by GO and KEGG and classified into $19 \mathrm{GO}$ terms. Of these, biological processes accounted for 10 terms, 
molecular functions accounted for 5 terms, and cellular components accounted for 4 terms. The most representative terms for each group included cellular processes GO: 0009987 and metabolic processes GO: 0008512; catalytic activity GO: 0003824 and binding GO: 0005488; and cell, membrane, and organelle, respectively (Fig. 7). KEGG pathway enrichment analysis revealed that most of these differential abundance proteins were largely involved in photosynthesis (map00195), carbon fixation in photosynthetic organisms (map00710), carbon metabolism (map01200), and glyoxylate and dicarboxylate metabolism (map00630; Fig. 7).

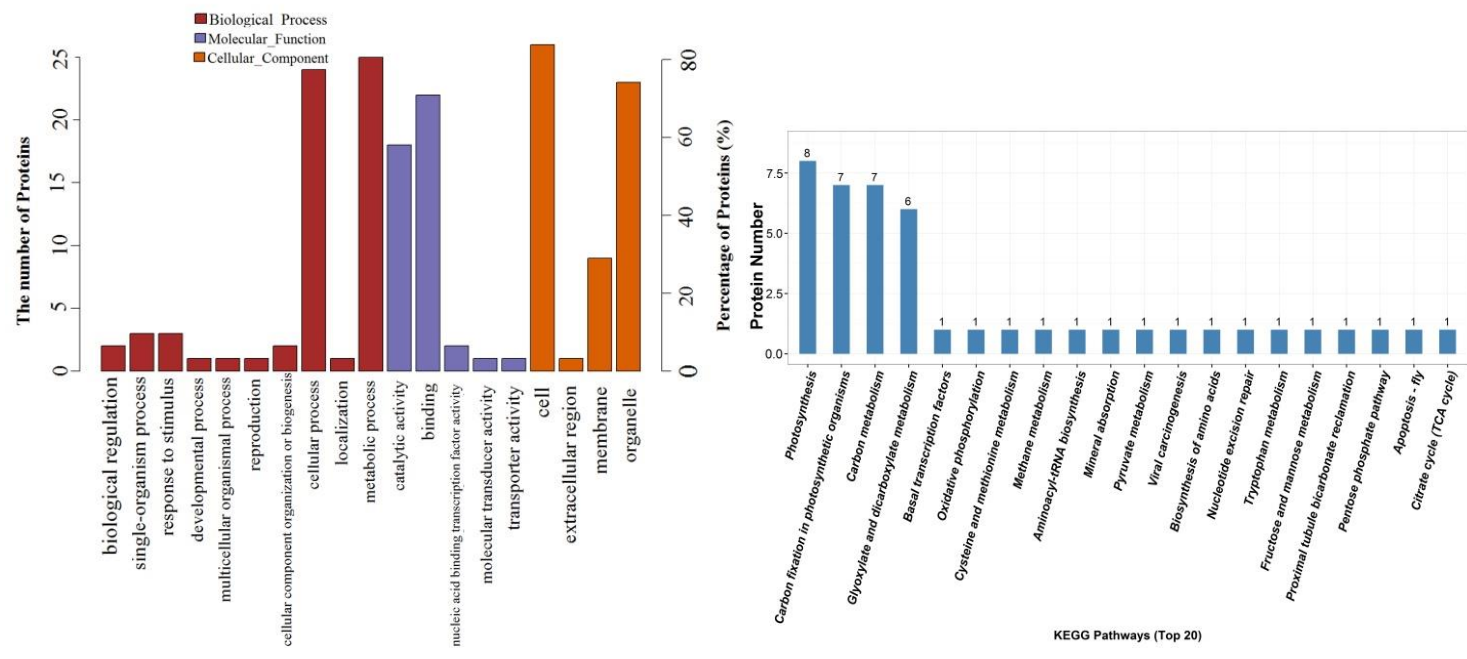

Figure 7. GO function and KEGG enrichment analysis of differential expression proteins. GO function classification (left); KEGG pathway enrichment (right)

\section{Discussion}

\section{Physiological analysis under drought stress}

Drought conditions intensify the various adverse effects such deficits have on plant characteristics, especially aspects related to effective soil water holding capacity, leading to irreparable leaf transpiration water loss and physical damage due to cell dehydration. These effects on plant morphological structure, physiological responses, and biochemical processes, including growth rate, stomatal conductance, tissue osmotic potential, and antioxidant defense, directly influence the normal growth and physiological processes of plants (Caruso et al., 2008; Xu et al., 2008). In this study, SWC and Pn were negatively influenced, showing a significant downward trend under prolonged drought stress. However, some fluctuations in Pn were observed on days 10 and 23, which can be attributed to fluctuations among several key environmental factors such as temperature and humidity during the treatment period. Under drought stress, the plant can decrease transpiration water loss rates by reducing stomatal conductance or through stomatal closure, although such measures also inhibit $\mathrm{CO}_{2}$ transport efficiency in leaf cells. Stomatal and non-stomatal limitation factors hinder plant photosynthesis; intercellular $\mathrm{CO}_{2}$ concentration (Ci) levels and stomatal limitation (Ls) rates can also help predict whether changes leading to Pn increases or decreases are primarily due to stomatal or non-stomatal limitations (Chaves et al., 2009; Lawlor and Tezara, 2009). Correlation analysis showed that $\mathrm{Pn}$, Gs, and $\mathrm{Tr}$ were significantly associated with bamboo LWP during drought stress (Table A2). This is because plant transpiration 
intensity can be influenced by both SWC and inner-outer leaf LWP. Additionally, the physiological state of the plant itself can also regulate transpiration. In this study, we found that leaf intercellular $\mathrm{CO}_{2}$ concentrations increased significantly $(P<0.05)$ during days 26-30, whereas Ls decreased significantly, indicating that the leaf cell structure had experienced certain levels of physical damage and illustrating the resultant photosynthetic shifts from stomatal to non-stomatal limitations.

Chlorophyll fluorescence kinetic parameters can be used to detect photosynthetic changes in plants under stress conditions quickly, accurately, and without damage to the plant leaf. Photosystem II (PSII) can be severely inhibited during drought stress. PSII also regulates electron transfer rates (ETR) and the efficiency of photochemical reactions in response to declines in carbon assimilation capacity and reduces the damage to plants caused by heat dissipation, called photoinhibition (Massacci et al., 2008). In this study, a slight increase in ETR and ФPSII, along with a decrease in Fm and $\mathrm{qN}$ were observed during drought stress days $0-10$, but these values did not change significantly, indicating that variation among chlorophyll fluorescence parameters is relatively small during periods of mild drought stress. D. minor var. amoenus may also maintain certain ETR and qN levels by regulating the function of photosynthetic organs structure in the leaves, as well as by reducing heat dissipation; a similar photosynthetic observation was noted in Gossypium hirsutum with the onset of drought stress (Massacci et al., 2008). After 10 days, fluorescence parameters ETR, ФPSII, and qN showed a significant decrease $(P<0.05)$, indicating that PSII had been damaged to varying degrees, photosynthetic organs and enzymes had been destroyed, and the effects of excess light energy could not be protected through heat dissipation. However, Kitao and Lei elucidated that cotton plants can reduce the risk of excessive energy in PSII by maintaining higher ETR associated with higher leaf nitrogen, even if Pn was reduced by stomatal closure (Kitao and Lei, 2007). Under drought conditions, when light use in photosynthesis or heat dissipation is not enough to deal with excessive energy levels, then large amounts of reactive molecules are produced, potentially leading to oxidative damage to photosynthetic organs (Dietz and Pfannschmidt, 2011).

Proline (PRO) is an ideal osmotic adjustment material that can both increase the osmotic potential of plant cells and promote plant cell absorption rates under drought conditions, reflecting plant stress resistance capacity (Seki et al., 2007). In this study, PRO content showed a significant increasing trend, a very sensitive response to stress, and a very large change range (Fig. 4), indicating that the plant could improve its drought resistance capacity by increasing PRO content to adjust leaf cell osmosis rates. PRO accumulation could firstly adjust cytoplasmic inner-outer osmosis differences to prevent the inactivation of intracellular proteins and enzymes under osmotic stress. Conversely, it could also eliminate excessive ROS produced by plant stress-response mechanisms. Additionally, PRO interacts with hydrophobic protein residues to regulate drought resistance (Nanjo et al., 1999; Seki et al., 2007). As elucidated above, decreased PSII activity causes excess light photo-inhibition and promotes the formation of excessive ROS, leading to peroxidation of membrane lipids and destruction of cell structures, which results in abnormal physiological metabolism in plant cells. A set of active oxygen species scavenging systems has been formed in plants in which SOD and CAT serve as important antioxidant enzymes, scavenging ROS such as $\mathrm{O}^{2-}, \mathrm{OH}^{-}$, and $\mathrm{H}_{2} \mathrm{O}_{2}$. Similarly, membrane lipid peroxidation rates increased due to ROS accumulation in plants under drought stress, resulting in increases in MDA content (one of the final products of lipid peroxidation), and reduction in the photosynthetic capacity of plant 
leaves (Hughes et al., 2001). In this study, significant increases in SOD and CAT activity were detected under mild stress conditions, which could eliminate ROS in cells and reduce membrane lipid peroxidation. However, SOD and CAT contents were inhibited and subsequently decreased under severe drought conditions (Fig. 4). Similarly, MDA levels continued to increase significantly, which seriously damaged PSII structure and function. Thus, it was proven that the primary factors for nonstomatal Pn limitation under drought stress were enzymatic systems and photosynthetic structures (Chaves et al., 2009). It was also noted that increased CAT content levels were higher than those related to SOD, which indicates that CAT is more sensitive to water deficit conditions.

\section{Protein involved in photosynthesis}

RuBisCO (ribulose-1, 5-bisphosphate carboxylase oxygenase) is an important enzyme involved in the carbon fixation process during photosynthesis, which converts $\mathrm{CO}_{2}$ to glucose in plants (Shi et al., 2014). RuBisCO also catalyzes RuBP, which is a primary reaction by which inorganic carbon enters the plant biosphere (Feller et al., 2007). In this study, four RuBisCO-associated proteins (spot 1: RuBisCO large subunit, spot 4: Ribulose bisphosphate carboxylase small chain, spot 5: RuBisCO small subunit $\mathrm{C}$, and spot 18: RuBisCO activase) were found to be downregulated in drought-affected bamboo leaves. Similar downregulation of RuBisCO-associated proteins was also found in rice leaf sheaths under drought stress (Yamane et al., 2003; Ali and Komatsu, 2006). Similarly, two different oxygen evolution enhancing protein configurations (spot 6 OEE1 and spot 23 OEE2) were highly upregulated, suggesting a putative role in OEE water stress response, whereas RuBisCo and OEE are more closely related to photosynthesis. Photoinhibition is the primary injury that plants experience under drought stress, along with photosynthetic decreases caused by stomatal or metabolic limitations ( $\mathrm{Xu}$ and Huang, 2010). RuBisCo subunit and RuBisCo activase are very important protein complexes highly prevalent in green plants. They are also the key enzymes related to photosynthesis and photorespiration in $\mathrm{C} 3$ plants; they are involved in both $\mathrm{CO}_{2}$ fixation (during photosynthesis) and $\mathrm{CO}_{2}$ release (during photorespiration). Both RuBisCo subunit and RuBisCo activase activity decreased as drought stress intensity increased. RuBisCo regeneration ability also decreased sharply, leading to decreases in photosynthetic rates. Jorge et al. (2006) investigated proteomic changes in Quercus ilex under drought stress at different growth stages in different provenances and found that both large and small RuBisCo subunits in leaves had decreased. The inhibition of, or decreases in, photosynthesis and chlorophyll fluorescence under water deficit conditions could be partially explained by such decreases in Rubisco subunits and Rubisco activase content. Additionally, OEE, which is a nuclear gene-encoded chloroplast protein, has three subunits (OEE1, OEE2, and OEE3). It is a peripheral protein in the PSII thylakoid membrane and plays an important role in water photolysis, possibly sustaining PSII oxygen release capacity (Xu et al., 2008). Furthermore, upregulated OEE was observed not only under drought stress but also in association with other abiotic stresses, such as salinity fluctuations (Gazanchian et al., 2007; Xu et al., 2010). OEE is very easy to separate from the PSII complex, resulting in increases in OEE1 and OEE2, as noted in the current study, and indicating repeat damage to the plants' photosynthetic systems. Similarly, PsbP (spot 30), a PSII oxygen-evolving complex peripheral protein in green plants, plays an important role in maintaining the oxygen releasing capacity and functional integrity of the photosynthetic system. 
Expression of PsbP increased in the oxygen releasing complexes of bamboo leaves under drought stress, indicating potential roles in maintaining the photosynthetic system and rate stability (Mohan et al., 1995).

Cytochrome b6-f complex metallothionein (spot 39) is a component of the cytochrome $b / f$ complex. This complex is a membrane protein that can be isolated from thylakoid membranes and consists of four polypeptides (cytochrome f, cytochrome b6, iron-sulfur protein, and polypeptide), among which the first three are electronic carriers. Cytochrome f, also known as c type cytochrome, is closely related to mitochondrial cytochrome c1, which is involved in the transfer of photosynthetic electron. In this study, levels of cytochrome b6-f complex metallothionein increased, indicating that the protein was separated from the thylakoid membrane complex and the photosynthetic electron conduction chain was blocked. Similar upregulation of cytochrome b6-f complex metallothionein was also associated with drought stress in Agrostis stolonifera (Xu and Huang, 2010).

\section{Proteins involved in energy metabolism}

The substantial decline in $\mathrm{CO}_{2}$ assimilation under water deficit conditions through the reduction in ATP levels indicated that ATP synthesis would respond to abiotic stress (Tezara et al., 1999; Deeba et al., 2012). ATP synthase, which is a key enzyme in plant energy metabolism, is widely distributed within plant chloroplasts, mitochondria, and nucleus, and provides energy requirements for metabolic activities, such as cell material transport, signal transduction, and material synthesis and decomposition. ATP synthase consists of two primary components, F0 and F1. F0 is located outside of the membrane and has three binding sites, comprised of five subunits. F1 is a transmembrane protein consisting of three subunits. ATP synthase CF1 beta subunit (spot 41) is an important component of ATP synthase, which participates in intracellular light and phosphorylation processes. The molecular functions of ATP synthase beta subunit CF1 involve the formation of non-covalent bonds between ATP and adenosine-5monophosphate. It is an important coenzyme and enzyme activity regulator; proton transfer ATP synthase activity coupled with rotation mechanisms, operating via transmembrane rotation and reverse electrochemical gradients to transport protons, form ATP. In this study, we found that the expression of ATP synthase subunit of CF1 synthase was downregulated under drought stress. However, contradictory results have been observed in mildly drought-stressed cotton (Deeba et al., 2012) and mildly saltstressed rice (Kim et al., 2005), in which CF1 beta subunit levels increased to enhance ATP synthesis capacity and alleviate damage to the chloroplasts and mitochondria. The authors attributed this to severe damage to the photosynthetic apparatus and metabolism enzyme inhibition during drought stress day 26. Detailed, time-interval delineated information related to this protein's response to drought conditions remains unclear in D. minor var. amoenus.

\section{Proteins involved in stress responses}

Germin-like protein (spot 40) is a kind of soluble glycoprotein that widely exists in plants. Germin-like protein is similar to Germin, which is primarily found in Triticum aestivum, both of which belong to the Cupin superfamily. Germin-like proteins are involved in many plant physiological and biochemical processes associated with enzymes, receptors, and structural proteins (Patnaik and Khurana, 2001). Germin-like 
protein may combine via ionic bonds in the extracellular matrix. Under stress conditions, the expression of germin-like proteins would be upregulated, and would then, in turn, regulate the signal transduction of $\mathrm{H}_{2} \mathrm{O}_{2}$ to protect the plant from oxidative damage. Additionally, this protein exhibits SOD-like activity, which can convert ROS into $\mathrm{H}_{2} \mathrm{O}_{2}$ in response to stress (Banerjee et al., 2010). Zhu et al. (2007) reported that expression levels of germin-like proteins were significantly increased in maize root cell walls under drought stress, indicating involvement in important roles in cell wall defense functions. Similar results were identified in Lupinus albus under drought stress. In this study, we found that the expression of the germin-like protein was upregulated under drought stress, which enhanced tolerance. Germin-like proteins were observed primarily through SOD and oxalate oxidase (OXO) functions under stress conditions. SOD could convert ROS into $\mathrm{H}_{2} \mathrm{O}_{2}$, and then be converted by peroxidase into $\mathrm{H}_{2} \mathrm{O}$, eliminating oxidase damage. OXO can catalyze oxalic acid to form $\mathrm{H}_{2} \mathrm{O}_{2}$ and $\mathrm{CO}_{2}$, and then eliminate it via a similar process. Additionally, induced $\mathrm{H}_{2} \mathrm{O}_{2}$ could mediate plant defense responses through signaling cascades and interactions with cellulose in the cell wall, enhancing cell wall stability during stress conditions (Zhu et al., 2007).

In this study, we also found enhanced expression levels of 2-Cys peroxiredoxin BAS1 (spot 22), which participates in the removal of ROS, antioxidant defenses, and redox signaling under stress conditions. 2-Cys peroxiredoxin BAS1 is a kind of typical cysteine peroxidase-reducing protein found in plant chloroplasts and was primarily cloned from Arabidopsis thaliana. Additionally, 2-Cys peroxiredoxin BAS1 content in mesophyll cells was found to be higher than that of vascular sheath cells. This is because mesophyll cells use linear photosynthetic electron transfer methods, leading to the generation of higher ROS content than sheath cells, and therefore accumulating higher redoxin protein levels in mesophyll cells (Baier and Dietz, 1997). In addition to $\mathrm{H}_{2} \mathrm{O}_{2}$ reduction, 2-Cys peroxiredoxin BAS1 can also reduce peroxide and peroxide nitroso. In this study, we found that the expression of 2-Cys peroxiredoxin BAS1 was upregulated, indicating a stress-related role in D. minor var. amoenus.

We also found a new expression of ferritin-1 (spot 10). Iron (Fe) atoms easily gain and lose electrons, which can lead to intense reactions when combined with oxygen atoms or other toxic substances. In plants, ferritins are located in the protoplast and are capable of forming a holographic surface that includes more than 4,500 Fe atoms. This structure indicates that ferritins play an important role in maintaining the balance of $\mathrm{Fe}$ atoms and protecting Fe-mediated oxidative reactions (Bournier et al., 2013). Four multi-gene families encoding ferritins were found in Arabidopsis, among which ferritin1 was the strongest response protein under iron stress. Under such conditions, ferritin-1 increased significantly from the transcriptional level to the final protein level in Arabidopsis, indicating that the ferritin-1 protein might also respond to abiotic stresses (Petit et al., 2001). In this study, ferritin-1 was newly expressed under drought conditions, suggesting a putative role in water deficit responses. Detailed information related to the different responses of this protein to drought-stress and iron-stress conditions requires further investigation.

\section{Conclusion}

This study provides an initial analysis of physiological and proteomic responses in leaves of the bamboo species, D. minor var. amoenus, under drought stress. Notably, the effects of mild drought stress on photosynthesis and chlorophyll fluorescence were 
lower than that of severe drought stress in this bamboo species, owing to compensation by other biological pathways. Severe drought stress causes leaf stomatal closure and accumulation of ROS, leading to physical damage to cell structure, while non-stomatal limitation factors assume leading roles in leaf photosynthesis and seriously affect the normal growth of plants. Analysis of stress response proteins revealed annotations of 23 upregulated, 13 downregulated, and 4 newly expressed proteins. Bioinformatics analysis showed that these differentially expressed proteins were related to photosynthesis, energy metabolism, and stress response, indicating the involvement of these proteins in response to drought stress in D. minor var. amoenus. The result of GO and KEGG classification analysis showed those differentially expressed proteins were related to photosynthesis, energy metabolism, and stress response, indicating the involvement of these proteins in response to drought stress in D. minor var. amoenus. Notably, the new expression of Ferritin-1, which reduces oxidative reactions, was studied Thus, there is a need to study the mechanism of Ferritin-1 in bamboo species under drought stress further. Taken together, these studies increase the understanding of response mechanisms of bamboo species under drought stress. Additionally, this study provides foundational information and an experimental basis for exploring drought resistance candidate genes among bamboo species.

Acknowledgements. This work was supported by the Central Fiscal Forestry Science and Technology Extension Project [2013, NO.7], the Science and Technology Major Projects of Fujian Province [2013NZ0001], the Regional Development Project of Fujian Province [2015N3015], and Program for Scientific and Technological Innovation Team for Universities of Fujian Province [2018, No.49].

\section{REFERENCES}

[1] Alam, I., Sharmin, S. A., Kim, K.-H., Yang, J. K., Choi, M. S., Lee, B.-H. (2010): Proteome analysis of soybean roots subjected to short-term drought stress. - Plant Soil 333: 491-505.

[2] Ali, G. M., Komatsu, S. (2006): Proteomic analysis of rice leaf sheath during drought stress. - J Proteome Res 5: 396-403.

[3] Aranjuelo, I., Molero, G., Erice, G., Avice, J. C., Nogués, S. (2010): Plant physiology and proteomics reveals the leaf response to drought in alfalfa (Medicago sativa L.). $-\mathbf{J}$ Exp Bot 62: 111-123.

[4] Baier, M., Dietz, K. (1997): The plant 2-Cys peroxiredoxin BAS1 is a nuclear-encoded chloroplast protein: its expressional regulation, phylogenetic origin, and implications for its specific physiological function in plants. - Plant J 12: 179-190.

[5] Banerjee, J., Das, N., Dey, P., Maiti, M. K. (2010): Transgenically expressed rice germin-like protein1 in tobacco causes hyper-accumulation of $\mathrm{H} 2 \mathrm{O} 2$ and reinforcement of the cell wall components. - Biochem Biophys Res Commun 402: 637-643.

[6] Bogeat-Triboulot, M.-B., Brosché, M., Renaut, J., Jouve, L., Le Thiec, D., Fayyaz, P., Vinocur, B., Witters, E., Laukens, K., Teichmann, T. (2007): Gradual soil water depletion results in reversible changes of gene expression, protein profiles, ecophysiology, and growth performance in Populus euphratica, a poplar growing in arid regions. - Plant Physiol 143: 876-892.

[7] Bota, J., Medrano, H., Flexas, J. (2004): Is photosynthesis limited by decreased Rubisco activity and RuBP content under progressive water stress? - New Phytol 162: 671-681.

[8] Bournier, M., Tissot, N., Mari, S., Boucherez, J., Lacombe, E., Briat, J.-F., Gaymard, F. (2013): Arabidopsis ferritin 1 (AtFer1) gene regulation by the phosphate starvation 
response 1 (AtPHR1) transcription factor reveals a direct molecular link between iron and phosphate homeostasis. - J Biol Chem 288: 22670-22680.

[9] Bradford, M. M. (1976): A rapid and sensitive method for the quantitation of microgram quantities of protein utilizing the principle of protein-dye binding. - Anal Biochem 72: 248-254.

[10] Caruso, A., Chefdor, F., Carpin, S., Depierreux, C., Delmotte, F. M., Kahlem, G., Morabito, D. (2008): Physiological characterization and identification of genes differentially expressed in response to drought induced by PEG 6000 in Populus canadensis leaves. - J Plant Physiol 165: 932-941.

[11] Caverzan, A., Casassola, A., Brammer, S. P. (2016): Antioxidant responses of wheat plants under stress. - Genet Mol Biol 39: 1-6.

[12] Chalker-Scott, L. (1999): Environmental significance of anthocyanins in plant stress responses. - Photochem Photobiol 70: 1-9.

[13] Chaves, M. M., Flexas, J., Pinheiro, C. (2009): Photosynthesis under drought and salt stress: regulation mechanisms from whole plant to cell. - Ann Bot 103: 551-560.

[14] Costa, P., Bahrman, N., Frigerio, J.-M., Kremer, A., Plomion, C. (1998): Water-deficitresponsive proteins in maritime pine. - Plant Mol Biol 38: 587-596.

[15] Deeba, F., Pandey, A. K., Ranjan, S., Mishra, A., Singh, R., Sharma, Y. K., Shirke, P. A., Pandey, V. (2012): Physiological and proteomic responses of cotton (Gossypium herbaceum L.) to drought stress. - Plant Physiol Biochem 53: 6-18.

[16] Dietz, K.-J., Pfannschmidt, T. (2011): Novel regulators in photosynthetic redox control of plant metabolism and gene expression. - Plant Physiol 155: 1477-1485.

[17] Ebrahimi-Birang, N., Fredlund, D. G. (2016): Assessment of the WP4-T device for measuring total suction. - Geotech Test J 39: 500-506.

[18] Fang, Y., Xiong, L. (2015): General mechanisms of drought response and their application in drought resistance improvement in plants. - Cell Mol life Sci 72: 673689.

[19] Feller, U., Anders, I., Mae, T. (2007): Rubiscolytics: fate of Rubisco after its enzymatic function in a cell is terminated. - J Exp Bot 59: 1615-1624.

[20] Gazanchian, A., Hajheidari, M., Sima, N. K., Salekdeh, G. H. (2007): Proteome response of Elymus elongatum to severe water stress and recovery. - J Exp Bot. 58: 291-300.

[21] Grassi, G., Magnani, F. (2005): Stomatal, mesophyll conductance and biochemical limitations to photosynthesis as affected by drought and leaf ontogeny in ash and oak trees. - Plant Cell Environ 28: 834-849.

[22] Hughes, S. M., Moroni-Rawson, P., Jolly, R. D., Jordan, T. W. (2001): Submitochondrial distribution and delayed proteolysis of subunit $\mathrm{c}$ of the $\mathrm{H}+$-transporting ATP-synthase in ovine ceroid-lipofuscinosis. - Electrophoresis 22: $1785-1794$.

[23] Jorge, I., Navarro, R. M., Lenz, C., Ariza, D., Jorrín, J. (2006): Variation in the holm oak leaf proteome at different plant developmental stages, between provenances and in response to drought stress. - Proteomics 6: S207-S214.

[24] Khaliq, M. A., Khan Tarin, M. W., Jingxia, G., Yanhui, C., Guo, W. (2019): Soil liming effects on $\mathrm{CH} 4, \mathrm{~N} 2 \mathrm{O}$ emission and $\mathrm{Cd}, \mathrm{Pb}$ accumulation in upland and paddy rice. - Environ Pollut 248: 408-420.

[25] Kim, D., Rakwal, R., Agrawal, G. K., Jung, Y., Shibato, J., Jwa, N., Iwahashi, Y., Iwahashi, H., Kim, D. H., Shim, I. (2005): A hydroponic rice seedling culture model system for investigating proteome of salt stress in rice leaf. - Electrophoresis 26: 45214539.

[26] Kitao, M., Lei, T. T., (2007): Circumvention of over-excitation of PSII by maintaining electron transport rate in leaves of four cotton genotypes developed under long-term drought. - Plant Biol 9: 69-76. 
[27] Koh, J., Chen, G., Yoo, M.-J., Zhu, N., Dufresne, D., Erickson, J. E., Shao, H., Chen, S. (2015): Comparative proteomic analysis of Brassica napus in response to drought stress. - J Proteome Res 14: 3068-3081.

[28] Kosová, K., Vítámvás, P., Prášil, I. T., Renaut, J. (2011): Plant proteome changes under abiotic stress-contribution of proteomics studies to understanding plant stress response. - J Proteomics 74: 1301-1322.

[29] Lawlor, D. W., Cornic, G. (2002): Photosynthetic carbon assimilation and associated metabolism in relation to water deficits in higher plants. - Plant Cell Environ 25: 275294.

[30] Lawlor, D. W., Tezara, W. (2009): Causes of decreased photosynthetic rate and metabolic capacity in water-deficient leaf cells: a critical evaluation of mechanisms and integration of processes. - Ann Bot 103: 561-579.

[31] Li, J., Ding, X., Han, S., He, T., Zhang, H., Yang, L., Yang, S., Gai, J. (2016): Differential proteomics analysis to identify proteins and pathways associated with male sterility of soybean using iTRAQ-based strategy. - J Proteomics 138: 72-82.

[32] Liu, H., Sultan MARF., Li Liu, X., Zhang, J., Yu, F., Xian Zhao, H. (2015): Physiological and comparative proteomic analysis reveals different drought responses in roots and leaves of drought-tolerant wild wheat (Triticum boeoticum). - PLoS One 10: e0121852.

[33] Liu, S., Wang, X., Wang, H., Xin, H., Yang, X., Yan, J., Li, J., Tran, L.-S. P., Shinozaki, K., Yamaguchi-Shinozaki, K. (2013): Genome-wide analysis of ZmDREB genes and their association with natural variation in drought tolerance at seedling stage of Zea mays L. - PLoS Genet 9: e1003790.

[34] Luna, C. M., Pastori, G. M., Driscoll, S., Groten, K., Bernard, S., Foyer, C. H. (2004): Drought controls on $\mathrm{H} 2 \mathrm{O} 2$ accumulation, catalase (CAT) activity and CAT gene expression in wheat. - J Exp Bot 56: 417-423.

[35] Massacci, A., Nabiev, S. M., Pietrosanti, L., Nematov, S. K., Chernikova, T. N., Thor, K., Leipner, J. (2008): Response of the photosynthetic apparatus of cotton (Gossypium hirsutum) to the onset of drought stress under field conditions studied by gas-exchange analysis and chlorophyll fluorescence imaging. - Plant Physiol Biochem 46: 189-195.

[36] Miao, Y., Lv, D., Wang, P., Wang, X.-C., Chen, J., Miao, C., Song, C.-P. (2006): An Arabidopsis glutathione peroxidase functions as both a redox transducer and a scavenger in abscisic acid and drought stress responses. - Plant Cell 18: 2749-2766.

[37] Mohan, P., Singh, P., Dongre, A. B., Narayanan, S. S. (1995): Gossypol-gland density and free gossypol content in seed and cotyledonary leaf of upland cotton (Gossypium hirsutum). - Indian J Agric Sci 65: 66-68

[38] Nanjo, T., Kobayashi, M., Yoshiba, Y., Sanada, Y., Wada, K., Tsukaya, H., Kakubari, Y., Yamaguchi-Shinozaki, K., Shinozaki, K. (1999): Biological functions of proline in morphogenesis and osmotolerance revealed in antisense transgenic Arabidopsis thaliana. - Plant J 18: 185-193.

[39] Patnaik, D., Khurana, P. (2001): Germins and germin like proteins: an overview. Indian J Exp Biol 39(3): 191-200.

[40] Petit, J.-M., van Wuytswinkel, O., Briat, J.-F., Lobréaux, S. (2001): Characterization of an Iron-dependent regulatory sequence involved in the transcriptional control of AtFer1 and ZmFer1 plant ferritin genes by iron. - J Biol Chem 276: 5584-5590.

[41] Rouhi, V., Samson, R., Lemeur, R., Van Damme, P. (2007): Photosynthetic gas exchange characteristics in three different almond species during drought stress and subsequent recovery. - Environ Exp Bot 59: 117-129.

[42] Seki, M., Umezawa, T., Urano, K., Shinozaki, K. (2007): Regulatory metabolic networks in drought stress responses. - Curr Opin Plant Biol 10: 296-302.

[43] Shi, H., Ye, T., Chan, Z. (2014): Comparative proteomic responses of two bermudagrass (Cynodon dactylon (L). Pers.) varieties contrasting in drought stress resistance. - Plant Physiol Biochem 82: 218-228. 
[44] Sobrado, M. A. (2011): Leaf gas exchange and fluorescence of two teosinte species: Zea mays ssp. parviglumis and Z. diploperennis. - J Trop Agric 49: 91-94.

[45] Tarin, M. W. K., Fan, L., Tayyab, M., Sarfraz, R., Chen, L., He, T., Rong, J., Chen, L., Zheng, Y. (2019): Effects of bamboo biochar amendment on the growth and physiological characteristics of Fokienia hodginsii. - Appl Ecol Environ Res 16: 80558074.

[46] Tarin, M. W. K., Lili, F., Lu, S., Jinli, L., Jingwen, L., Zhiwen, D., Lingyan, C., Tianyou, H., Rong, J., Zheng, Y. (2020): Rice straw biochar impact on physiological and biochemical attributes of Fokienia hodginsii in acidic soil. - Scand J For Res 0(0): 1-10. https://doi.org/10.1080/02827581.2020.1731591.

[47] Tayyab, M., Islam, W., Khalil, F., Ziqin, P., Caifang, Z., Arafat, Y., Hui, L., Rizwan, M., Ahmad, K., Waheed, S., et al. (2018): Biochar: an efficient way to manage low water availability in plants. - Appl Ecol Environ Res 16(3): 2565-2583.

[48] Tong, R., Zhou, B., Cao, Y., Ge, X., Jiang, L. (2020): Metabolic profiles of moso bamboo in response to drought stress in a field investigation. - Science of the Total Environment 720 .

[49] Tezara, W., Mitchell, V. J., Driscoll, S. D., Lawlor, D. W. (1999): Water stress inhibits plant photosynthesis by decreasing coupling factor and ATP. - Nature 401: 914.

[50] Thalmann, M., Santelia, D. (2017): Starch as a determinant of plant fitness under abiotic stress. - New Phytologist 214(3): 03-10.

[51] Wang, W., Vignani, R., Scali, M., Cresti, M. (2006): A universal and rapid protocol for protein extraction from recalcitrant plant tissues for proteomic analysis. Electrophoresis 27: 2782-2786.

[52] Wang, W.-B., Kim, Y.-H., Lee, H.-S., Kim, K.-Y., Deng, X.-P., Kwak, S.-S. (2009): Analysis of antioxidant enzyme activity during germination of alfalfa under salt and drought stresses. - Plant Physiol Biochem 47: 570-577.

[53] Wu, X.-P., Liu, S., Luan, J., Wang, Y., Cai, C. (2019): Responses of water use in Moso bamboo (Phyllostachys heterocycla) culms of different developmental stages to manipulative drought. - For Ecosyst 6(1): 1-14.

[54] Xu, C., Huang, B. (2010): Differential proteomic responses to water stress induced by PEG in two creeping bentgrass cultivars differing in stress tolerance. - J Plant Physiol 167: $1477-1485$.

[55] Xu, C., Sibicky, T., Huang, B. (2010): Protein profile analysis of salt-responsive proteins in leaves and roots in two cultivars of creeping bentgrass differing in salinity tolerance. - Plant Cell Rep 29: 595-615.

[56] Yamane, K., Hayakawa, K., Kawasaki, M., Taniguchi, M., Miyake, H. (2003): Bundle sheath chloroplasts of rice are more sensitive to drought stress than mesophyll chloroplasts. - J Plant Physiol 160: 1319.

[57] Yan, J. X., Wait, R., Berkelman, T., Harry, R. A., Westbrook, J. A., Wheeler, C. H., Dunn, M. J. (2000): A modified silver staining protocol for visualization of proteins compatible with matrix-assisted laser desorption/ionization and electrospray ionization-mass spectrometry. - Electrophor An Int J 21: 3666-3672.

[58] Yang, A., Dai, X., Zhang, W.-H. (2012): A R2R3-type MYB gene, OsMYB2, is involved in salt, cold, and dehydration tolerance in rice. - J Exp Bot 63: 2541-2556.

[59] Zhu, J., Alvarez, S., Marsh, E. L., LeNoble, M. E., Cho, I.-J., Sivaguru, M., Chen, S., Nguyen, H. T., Wu, Y., Schachtman, D. P. (2007): Cell wall proteome in the maize primary root elongation zone. II. Region-specific changes in water soluble and lightly ionically bound proteins under water deficit. - Plant Physiol 145: 1533-1548.

[60] Zou, J.-J., Wei, F.-J., Wang, C., Wu, J.-J., Ratnasekera, D., Liu, W.-X., Wu, W.-H. (2010): Arabidopsis calcium-dependent protein kinase CPK10 functions in abscisic acid-and $\mathrm{Ca} 2+$-mediated stomatal regulation in response to drought stress. - Plant Physiol 154: 1232-1243. 


\section{APPENDIX}

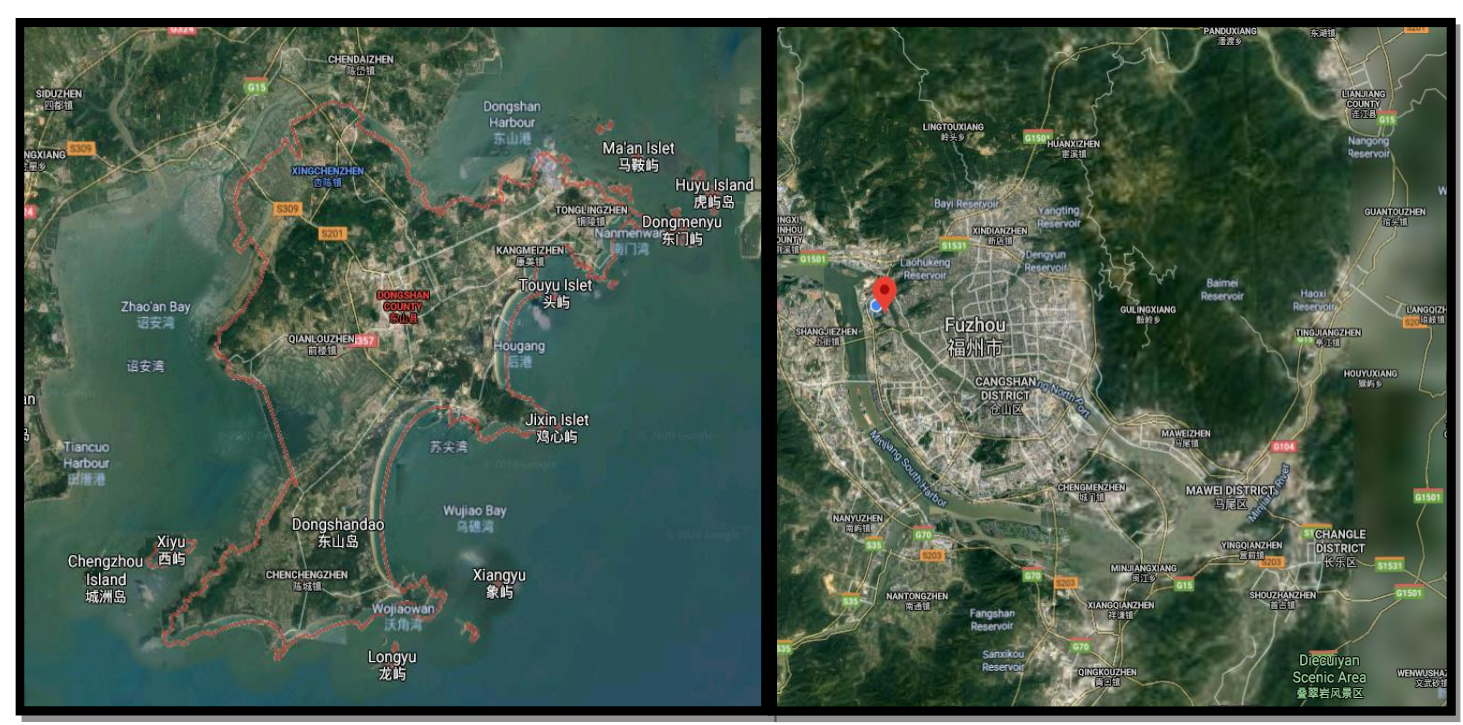

Figure A1. Map showing the bamboo coastal sandy protection areas of Dongshan Island (left) and Bamboo Research Institute of the Fujian Agriculture and Forestry University, Fuzhou,

China (right)

Table A1. Changes in soil water content (SWC) and leaf water potential (LWP) under drought stress

\begin{tabular}{c|c|c|c|c}
\hline \multirow{2}{*}{ Stress (days) } & \multicolumn{2}{|c|}{ SWC (\%) } & \multicolumn{2}{c}{ LWP $(\mathbf{M P a})$} \\
\cline { 2 - 5 } & Treatment & Control & Treatment & Control \\
\hline 0 & $30.867 \pm 1.858 \mathrm{f}$ & $30.867 \pm 1.858 \mathrm{a}$ & $-1.143 \pm 0.101 \mathrm{~h}$ & $-1.237 \pm 0.075 \mathrm{a}$ \\
5 & $22.267 \pm 1.498 \mathrm{e}$ & $30.567 \pm 2.793 \mathrm{a}$ & $-2.037 \pm 0.097 \mathrm{~g}$ & $-1.05 \pm 0.105 \mathrm{a}$ \\
10 & $14.2 \pm 0.9 \mathrm{~d}$ & $32.433 \pm 3.889 \mathrm{a}$ & $-2.853 \pm 0.078 \mathrm{f}$ & $-1.237 \pm 0.095 \mathrm{a}$ \\
15 & $6.267 \pm 0.896 \mathrm{c}$ & $37.733 \pm 0.252 \mathrm{~b}$ & $-3.35 \pm 0.325 \mathrm{e}$ & $-1.043 \pm 0.196 \mathrm{a}$ \\
20 & $4.6 \pm 0.436 \mathrm{c}$ & $31.867 \pm 2.346 \mathrm{a}$ & $-3.983 \pm 0.123 \mathrm{~d}$ & $-1.207 \pm 0.195 \mathrm{a}$ \\
23 & $2.633 \pm 0.85 \mathrm{~b}$ & $30.967 \pm 1.38 \mathrm{a}$ & $-4.427 \pm 0.165 \mathrm{c}$ & $-1.087 \pm 0.12 \mathrm{a}$ \\
26 & $0.833 \pm 0.058 \mathrm{a}$ & $31.5 \pm 0.954 \mathrm{a}$ & $-4.93 \pm 0.229 \mathrm{~b}$ & $-1.213 \pm 0.112 \mathrm{a}$ \\
30 & $0.433 \pm 0.058 \mathrm{a}$ & $32.9 \pm 1.572 \mathrm{a}$ & $-5.65 \pm 0.161 \mathrm{a}$ & $-1.187 \pm 0.11 \mathrm{a}$ \\
\hline
\end{tabular}

Measurements were conducted at each sampling time over the treatment. Each value represent means \pm standard error of three replicate experiments. Data denoted by the same letter did not differ at significant levels $(P<0.05)$ according to Duncan's multiple range test

Table A2. Correlation coefficients between photosynthetic parameters, SWC and LWP

\begin{tabular}{c|c|c|c|c|c|c|c}
\hline & LWP & SWC & Pn & Gs & Ci & Tr & PWUE \\
\hline SWC & $0.985^{* *}$ & & & & & & \\
Pn & $0.899^{* *}$ & $0.904^{* *}$ & & & & & \\
Gs & $0.921^{* *}$ & $0.910^{* *}$ & $0.953^{* *}$ & & & & \\
Ci & 0.170 & 0.167 & 0.196 & 0.274 & & & \\
Tr & $0.910^{* *}$ & $0.908^{* *}$ & $0.914^{* *}$ & $0.962^{* *}$ & 0.302 & & \\
PWUE & 0.195 & 0.220 & 0.375 & 0.180 & $-0.613^{* *}$ & 0.076 & \\
LS & -0.170 & -0.167 & -0.196 & -0.274 & $-1.000^{* *}$ & -0.302 & $0.613^{* *}$ \\
\hline
\end{tabular}

Parameters include net photosynthetic rate $(\mathrm{Pn})$, stomatal conductance $(\mathrm{Gs})$, transpiration rate (Tr), intercellular $\mathrm{CO}_{2}$ concentration (Ci), water use efficiency (PWUE), soil water content (SWC) and leaf water potential (LWP). ** Correlation is significant at the 0.01 significance level 
Table A3. Differential protein spots identified by MALDI-TOF-MS under drought stress

\begin{tabular}{|c|c|c|c|c|c|c|c|c|}
\hline $\begin{array}{c}\text { Sample } \\
\text { spot }\end{array}$ & $\begin{array}{c}\text { Corresponding } \\
\text { target }\end{array}$ & Protein name & Accession NO. & Sources & $\begin{array}{l}\text { Theor } \\
\text { MW }\end{array}$ & $\mathrm{p} I$ & \begin{tabular}{|l|}
$\begin{array}{l}\text { Peptide } \\
\text { matches }\end{array}$ \\
\end{tabular} & C.I.\% \\
\hline 1 & M19 & Ribulose-1,5-bisphosphate carboxylase/oxygenase large subunit (plastid) & gi|817525241 & Neohouzeaua sp. Clark \& Attigala 1712 & 52851.5 & 6.3299 & 16 & 100 \\
\hline 2 & M20 & Hypothetical protein OsJ_35814 & gi| 125579068 & Oryza sativa Japonica Group & 19485.9 & 8.87 & 9 & 100 \\
\hline 3 & M21 & Hypothetical protein OsI_38046 & gi $\mid 125536346$ & Oryza sativa Japonica Group & 19708 & 9.04 & 9 & 100 \\
\hline 4 & M22 & Ribulose bisphosphate carboxylase small chain, chloroplastic & gi|122234140 & Oryza sativa Japonica Group & 19633.9 & 9.04 & 9 & 100 \\
\hline 5 & M23 & RuBisCO small subunit $\mathrm{C}$ & gi 158513174 & Oryza sativa Indica Group & 19633.9 & 9.04 & 7 & 100 \\
\hline 6 & M24 & Oxygen-evolving enhancer protein 1 , chloroplastic & gi|474352688 & Triticum urartu & 34407.4 & 5.75 & 10 & 100 \\
\hline 7 & N1 & Hypothetical protein & gi|226506316 & Zea mays & 24474.4 & 4.99 & 6 & 100 \\
\hline 9 & N3 & Hypothetical protein OsJ_01921 & gi|125570526 & Oryza sativa Japonica Group & 34839.7 & 6.1 & 10 & 100 \\
\hline 10 & $\mathrm{~N} 4$ & Ferritin-1, chloroplastic-like & gi|514807458 & Setaria italica & 27984.2 & 5.67 & 4 & 100 \\
\hline 12 & N6 & Uncharacterized protein & V4W9U6_9ROSI & Citrus clementina & 42274.6 & 9 & 15 & 95.617 \\
\hline 13 & N7 & Hypothetical protein OsJ_01921 & gi|125570526 & Oryza sativa Japonica & 34839.7 & 6.1 & 7 & 100 \\
\hline 14 & N8 & Transcription factor-related family protein & B9H470_POPTR & Populus trichocarpa & 66182.6 & 6.25 & 21 & 97.77 \\
\hline 16 & N10 & Ribosome-recycling factor, chloroplastic & gi|474043078 & Triticum urartu & 24755.2 & 8.92 & 5 & 100 \\
\hline 17 & N11 & Uncharacterized protein & W5BGE9_WHEAT & Triticum aestivum & 40596.1 & 9.03 & 7 & 96.716 \\
\hline 18 & N12 & Ribulose bisphosphate carboxylase/oxygenase activase & gi|109940135 & Oryza sativa Japonica Group & 51421.4 & 5.4299 & 14 & 100 \\
\hline 19 & N13 & Hypothetical protein OsJ_01921 & gi $\mid 125570526$ & Oryza sativa Japonica Group & 34839.7 & 6.1 & 4 & 100 \\
\hline 20 & N14 & Hypothetical protein OsI_25003 & gi|218199135 & Oryza sativa Indica Group & 108971.8 & 6.04 & 25 & 96.175 \\
\hline 21 & N15 & Extra-large guanine nucleotide-binding protein 3 -like isoform X2 & gi|514817425 & Setaria italica & 70472.4 & 5.43 & 17 & 95.716 \\
\hline 22 & N16 & 2-Cys peroxiredoxin BAS1, chloroplastic & gi|514713083 & Setaria italica & 28032.5 & 5.97 & 5 & 99.785 \\
\hline 23 & N17 & Oxygen-evolving enhancer protein 2 , chloroplastic & gi|474077556 & Triticum urartu & 25485.8 & 8.94 & 7 & 100 \\
\hline 26 & $\mathrm{~N} 20$ & Eukaryotic translation initiation factor 3 subunit A & gi|514774931 & Setaria italica & 114747.4 & 9.27 & 15 & 90.854 \\
\hline 29 & $\mathrm{~N} 23$ & Calcium-dependent protein kinase, isoform AK1 & gi|728449015 & Arundo donax & 2282 & 12 & 5 & 94.457 \\
\hline 30 & $\mathrm{~N} 24$ & Chain A, The Crystal Structure of Psbp & gi|767259516 & Zea Mays & 20117.2 & 5.96 & 5 & 100 \\
\hline 31 & O1 & Malate dehydrogenase, cytoplasmic & gi|514816242 & Setaria italica & 35461.1 & 5.76 & 9 & 100 \\
\hline 32 & $\mathrm{O} 2$ & Predicted protein & A9T5M7_PHYPA & Physcomitrella patens subsp. & 141967.7 & 6.28 & 31 & 98.102 \\
\hline 33 & $\mathrm{O} 3$ & Fructose-bisphosphate aldolase & gi|514804765 & Setaria italica & 41808.5 & 6.08 & 13 & 100 \\
\hline 34 & $\mathrm{O} 4$ & rcal & gi|728675519 & Arundo donax & 44304.1 & 5.5 & 7 & 100 \\
\hline 35 & O5 & Flavin-containing monooxygenase & A0A059AY33_EUCGR & Eucalyptus grandis & 42130.6 & 8.77 & 18 & 98.908 \\
\hline 37 & O7 & Hypothetical protein OsI_28915 & gi|218201012 & Oryza sativa Indica Group & 26987.8 & 8.76 & 6 & 96.668 \\
\hline 38 & O8 & Glutathione S-transferase DHAR3, chloroplastic & gi|514762575 & Setaria italica & 28944.1 & 7.68 & 7 & 98.992 \\
\hline 39 & O9 & Cytochrome b6-f complex iron-sulfur subunit, chloroplastic & gi $\mid 475511555$ & Aegilops tauschii & 23711 & 8.47 & 5 & 100 \\
\hline 40 & $\mathrm{O} 10$ & Germin-like protein 8-14 & gi|475618322 & Aegilops tauschii & 25959.6 & 8.43 & 3 & 99.887 \\
\hline 41 & O11 & ATP synthase CF1 beta subunit (plastid) & gi $\mid 817524800$ & Bambusa arnhemica & 53879.2 & 5.4699 & 26 & 100 \\
\hline
\end{tabular}

The differentially expressed proteins were calculated according to statistically significant changes between samples using SPSS software by ANOVA-test (abundance variation at least 2-fold, $\mathrm{p}<0.05$ ). The sample spot represents the number of proteins assigned in Figures 5 and 6. Theor MW and pI values shown are the theoretical and experimental values. C.I.\%, which is the Mascot score of the in-solution digestion protocol. Accession number and Protein name are assigned according to the NCBInr-protein sequence database 